\title{
Nanotechnology of "intellectualization" of energy accounting and of suppression of fire-energy harm in engineering systems of residential buildings. Part 1
}

\author{
V.V. Belozerov ${ }^{1 *}$ (D) VI.V. Belozerov ${ }^{1}$ (D) T.B. Dolakov² (D, M.A. Nikulin ${ }^{3}$ (D) , S. N. Oleinikov² (iD) \\ ${ }^{1}$ Don State Technical University, Rostov-on-Don, Russia \\ ${ }^{2}$ Academy of the State Fire Service of the EMERCOM of Russia, Moscow, Russia \\ ${ }^{3}$ State Agrarian University of the Northern Trans-Urals, Tyumen, Russia \\ * Corresponding author: e-mail: safeting@mail.ru
}

\begin{abstract}
Introduction. Currently, both abroad and in Russia, there is a "general digitalization" not only of certain types of activities, but also of objects of the technosphere, for example, "smart houses", "safe cities", etc. However, the "creators" of these objects violated the main principle of automation of Academician V.M. Glushkov, which says: you cannot automate the mess! Therefore, the authors of this article made an attempt to "eliminate clutter" in the automation of engineering systems in the residential sector. Methods, models and tools. Based on the analysis of the engineering systems of multi-apartment residential buildings and individual residential buildings, as a result of the functioning of which not only the delivery of "life support benefits" is carried out, but also fire-energy and environmental damage occurs, a methodology for "intellectualization" of the accounting means for the supplied resources has been developed for diagnostics and suppression of fire and energy harm with the help of modern nanotechnology and, thus, prevention of fires and explosions in the residential sector.

Results and discussion. The methodology of "intellectualization" is based on the results of a system analysis of the "functioning of the residential sector" (apartment buildings and individual residential buildings), which made it possible to "discover" the dialectical unity of benefits and harms from consumed energy resources (electricity, domestic gas, hot and cold water), as well as to carry out a systemic synthesis of nanotechnologies and means of "isolation and suppression" of fire and energy harm. The novelty of the research is protected by RF patents.

Conclusion. The proposed approach allows "eliminating the disorder before the automation" of engineering systems of multiapartment residential buildings and individual residential buildings, by "intellectualizing" metering devices and optimizing nanotechnologies for suppressing fire and energy harm that brings socio-economic losses.

KEY WORDS: automation, engineering systems of buildings, fire and energy harm, diagnostics of fire and explosion hazard, electric meter-detector, reactive power compensator, membrane air separator, thermomagnetic air separator.

FOR CITATION: Belozerov V.V., Belozerov VI.V., Dolakov T.B., Nikulin M.A., Oleinikov S.N. Nanotechnologies of "intellectualization" of energy accounting and of suppression of fire-energy harm in engineering systems of residential buildings. Part 1. Nanotechnologies in Construction. 2021; 13(2): 95-107. Available from: doi: 10.15828/2075-8545-2021-13-2-95-107.
\end{abstract}

\section{INTRODUCTION}

A ccording to statistics from the All-Russian Research Institute for Fire Protection of the Ministry of Emergency Situations of Russia, about $70 \%$ of fires occur annually in the residential sector of the country [1]:

- in 1-2 storey buildings - up to 125 thousand fires and up to 10 thousand dead,
- in 3-5 storey buildings - about 20 thousand fires and about 2 thousand dead,

- in 6-9 storey buildings - about 16 thousand fires and up to 1 thousand dead,

- in 10-25 storey buildings - about 10 thousand fires and about 500 dead,

- in buildings over 25 floors - about 30 fires and up to 10 dead.

(c) Belozerov V.V., Belozerov VI.V., Dolakov T.B., Nikulin M.A., Oleinikov S.N., 2021 


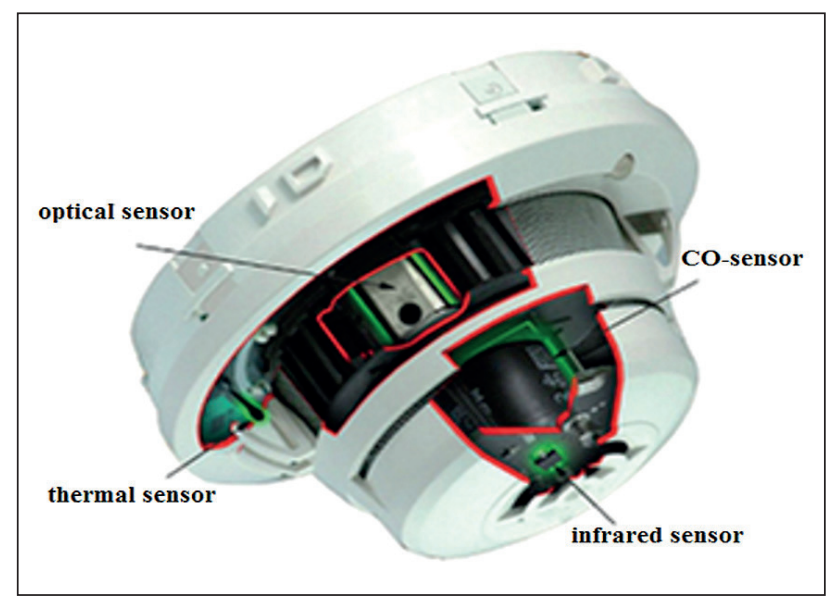

Fig. 1. Multi-sensor

If we introduce the concept of "the probability of death from the number of storeys of a building", i.e. the ratio of the death toll to the number of stores, then in high-rise buildings it is 4.16 times higher than 1-2 storeys buildings. And this is despite the fact that capital fireprevention measures are provided for in buildings above 10 floors (smoke-free staircases, etc.) [2].

In many countries of the world (USA, Germany, Poland, Russia, etc.) in recent decades, autonomous fire detectors (AFD) have become widespread, installed in protected premises, which, when signs of fire are detected, an intermittent alarm signal with a sound pressure level of 85-90 dB at a distance of $1 \mathrm{~m}$ from the detector. Statistics show that the use of AFD can reduce the number of deaths in fires in the residential sector at night by $45 \%$ [3].
There are many known methods and devices for detecting fires that implement these methods [4]:

- Smoke fire detectors - ionization and optical;

- Thermal fire detectors - threshold and analog;

- Flame detectors - optical and based on the use of ultraviolet or infrared radiation;

- Gas fire detectors - for combustion products, including selective linear ones.

The most effective of these are detectors that combine photoelectric, thermal and gas sensors. Similar types of multi-sensors (Fig. 1) have been used for a long time, using very simple ("or-or") and combined ("and-andor-and") decision-making methods in case of triggering of sensitive elements [5-8].

The fact is that different models of the temperature regime of fire development are used abroad. So, for example, the first American standard (now E119), was published in 1918, and its standard curve is almost identical to the British Standard (BS) curve, published in 1932 (Fig. 2a), which is described by the formula [9]:

$$
T=T_{0}+345 \log (0.133 t+1)
$$

where $\mathrm{T}$ is the room temperature, ${ }^{\circ} \mathrm{C} ; \mathrm{T}_{0}-$ temperature in the room at the time of ignition, ${ }^{\circ} \mathrm{C} ; \mathrm{t}-$ time, sec.

The standard temperature-time curve of a fire in a room ISO 834 (Fig. 2b) is described by the system [9]:

$$
T= \begin{cases}T_{0}+504 t^{0.141} & \text { at } \mathrm{t}<10 \text { minutes } \\ T_{0}+345 \log (8 \tau+1) & \text { at } \mathrm{t}>10 \text { minutes. }\end{cases}
$$
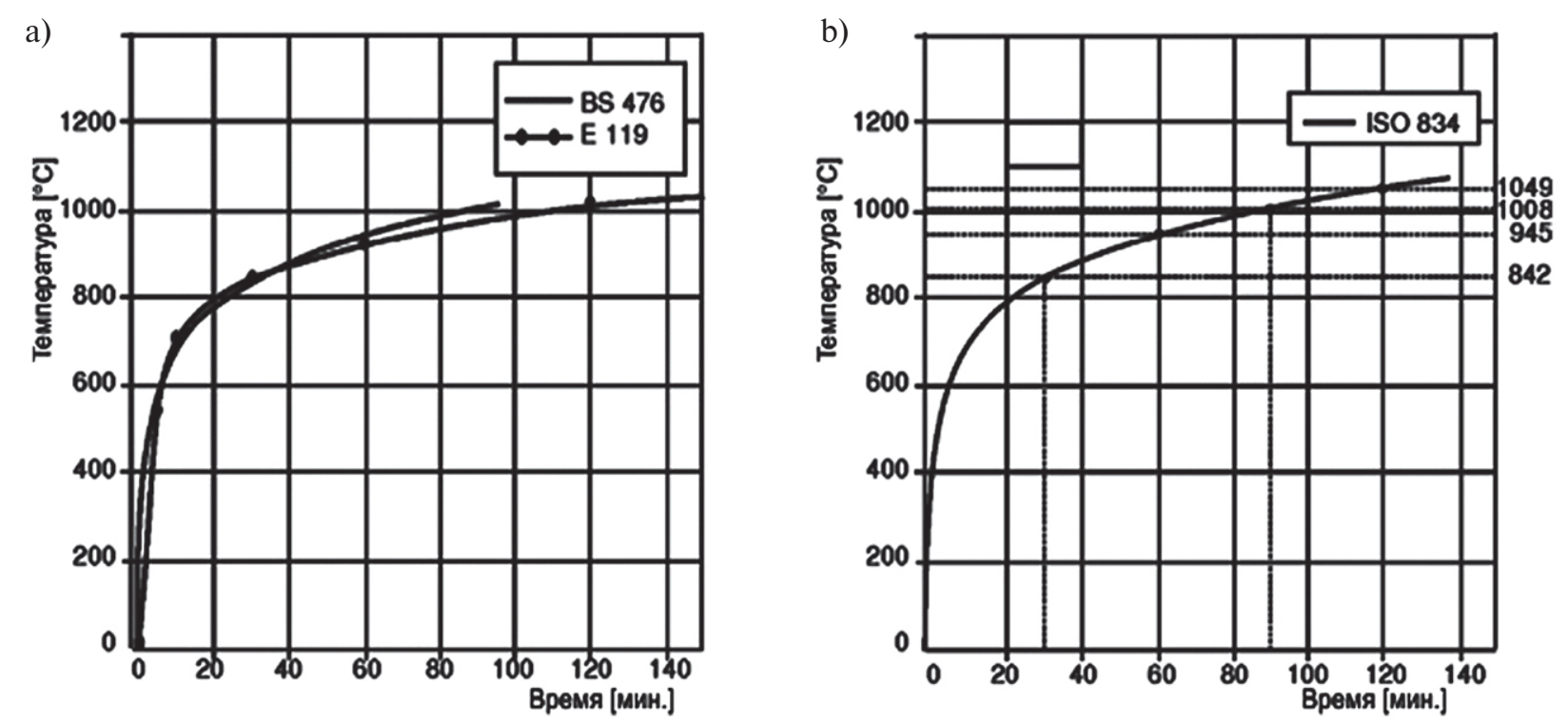

Fig. 2. Temperature curves of the US and UK (a) and European (b) standards 
In our country, the generally accepted modeling of the temperature regime of fire development is carried out according to the equation [10]:

$$
T=345 \lg (8 t+1)+T_{0}
$$

where $\mathrm{T}$ is temperature, ${ }^{\circ} \mathrm{C} ; \mathrm{t}-$ time, $\min ., \mathrm{T}_{0}-$ room temperature at the moment of ignition, ${ }^{\circ} \mathrm{C}$.

As follows from the graph of equation (2), its derivative (Fig. 3) has neither maxima nor minima, since is a hyperbolic function asymptotically approaching the " $\mathrm{t}$ " axis. This does not allow using with help the thermal sensor to unambiguously identify the initial stage of the fire, which leads to false alarms of thermal fire detectors [3, 4].

Normalized values (table 1) of hazardous fire factors (HFF) and graphs of functions of their main components (Fig. 4-6), obtained using the INTMODEL program (numerical solution of the system of differential equations by the Runge-Kutta-Felberg method of 4-5 orders of magnitude with variable step), allow us to make the following assumptions - if the same multi-sensor (Fig. 1) is to supplement with an oxygen sensor, then it is possible to identify the occurrence of a fire at the initial stage of ignition, due to the presence of extreme`s points on it [10-12].

However, the use of a multi-sensor with the calculation of the indicated extreme's (Fig. 4-6) has great inertia, because it will register hazardous factors of fire or explosion (HFFE) when they "reach" sensitive elements, which, as a rule, are installed on ceilings, in connection with which, "arrival to them" of HFFE ranges from several units to tens of minutes [7]. Therefore, for the early detection of HFFE, an aspiration method was invented [13] and a system that implements it, usually called "flowing" (Fig. 7).

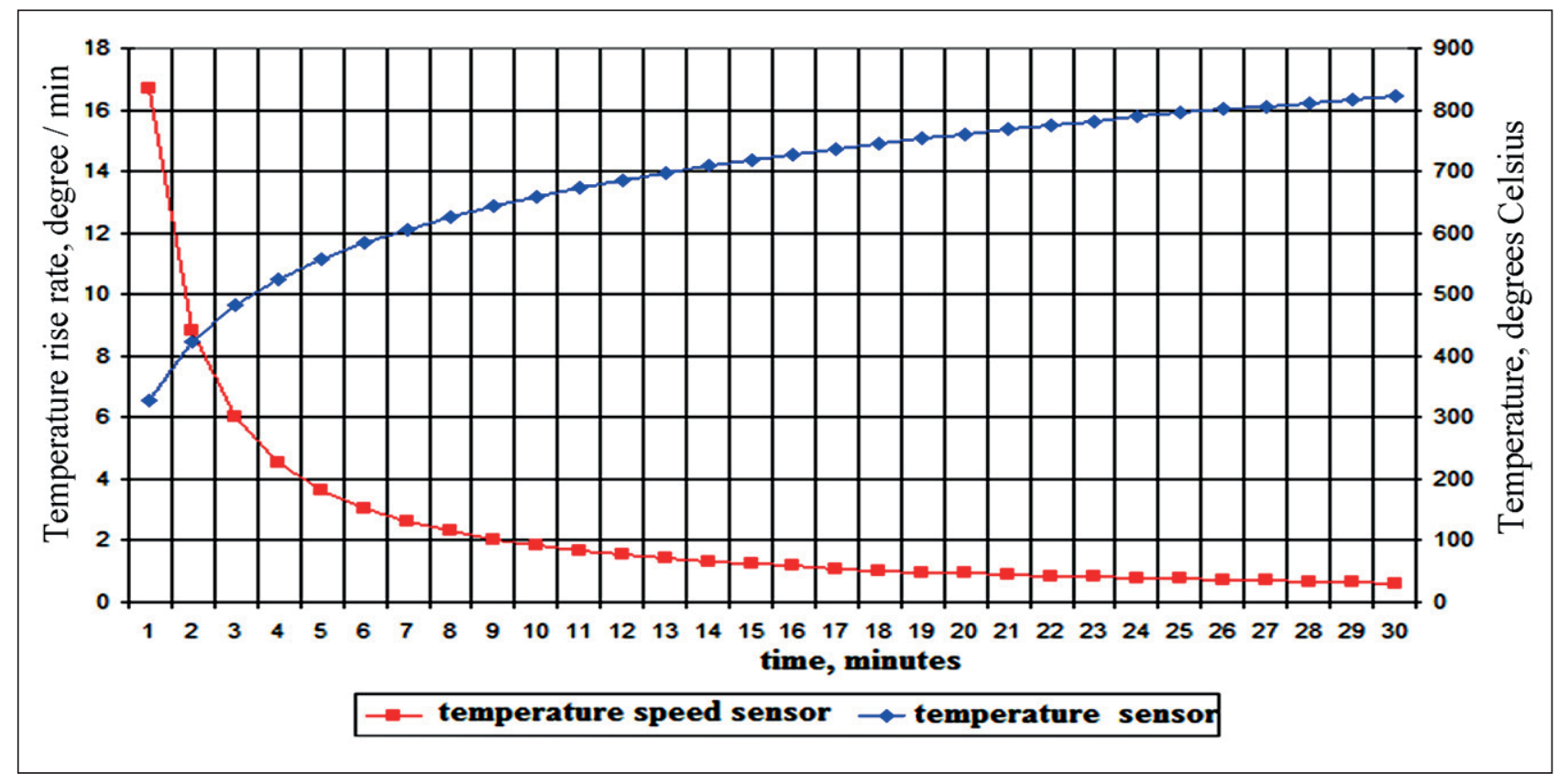

Fig. 3. Graphs of "standard fire"

\section{Table 1}

\begin{tabular}{|c|l|c|}
\hline №, $\mathbf{p} / \mathbf{p}$ & \multicolumn{1}{|c|}{ Hazardous factor of fire Limit value } & Limit value \\
\hline 1 & Carbon monoxide (carbon monoxide gas) $-\mathrm{CO}$ & $1.16 \mathrm{~g} / \mathrm{m}^{3}(0.1 \%$ volume $)$ \\
\hline 2 & Carbon dioxide (carbon dioxide gas) $-\mathrm{CO}_{2}$ & $0.00011 \mathrm{~g} / \mathrm{m}^{3}$ \\
\hline 3 & Hydrogen chloride & $0.000023 \mathrm{~g} / \mathrm{m}^{3}$ \\
\hline 4 & Temperature & $70^{\circ} \mathrm{C}$ \\
\hline 5 & Intensity of heat radiation & $1,4 \mathrm{~kW} / \mathrm{m}^{2}$ \\
\hline 6 & Oxygen concentration & $15 \%$ \\
\hline 7 & Ultimate visibility in smoke & $20 \mathrm{~m}$ \\
\hline
\end{tabular}


The essence of the method lies in the fact that standard sensors are installed in a chamber connected to a pipeline with special holes, which are situated in the protected premises, and the air of the protected premises is "pumped" through it by a fan. That is, if hazardous factors of fire or explosion (HFFE) arise, they are "drawn into the sensors" and are detected faster by an order of magnitude $[4,13]$.

At the same time, the performed studies have determined that the low quality of electricity consumed by electrical appliances (for example, low or high voltage, phase shift of current and voltage, etc.) reduces the technical resource of household electrical appliances and creates conditions for the occurrence of fire hazardous failures in them, i.e. increases the likelihood of fires for electrical reasons [14].
One of the first inventions in the field of determining the "shares of high-quality and low-quality" consumed electricity was the "Statistical analyzer of the quality and metering of electricity consumption" [15], where, when measuring and digitizing the alternating current voltage of curve of the network, deviations from the values set by standard [16] were identified, which were recorded, and after the required time (day, week, month) had elapsed, and were determined by formula:

$$
\mathrm{W}=\mathrm{Wpd}+\mathrm{Wud},
$$

where $\mathrm{W}$ is the total amount of electricity supplied to the consumer during the time T; Wpd - the amount of consumed electricity with permissible deviations; Wud - the amount of consumed electricity in case of unacceptable deviations.

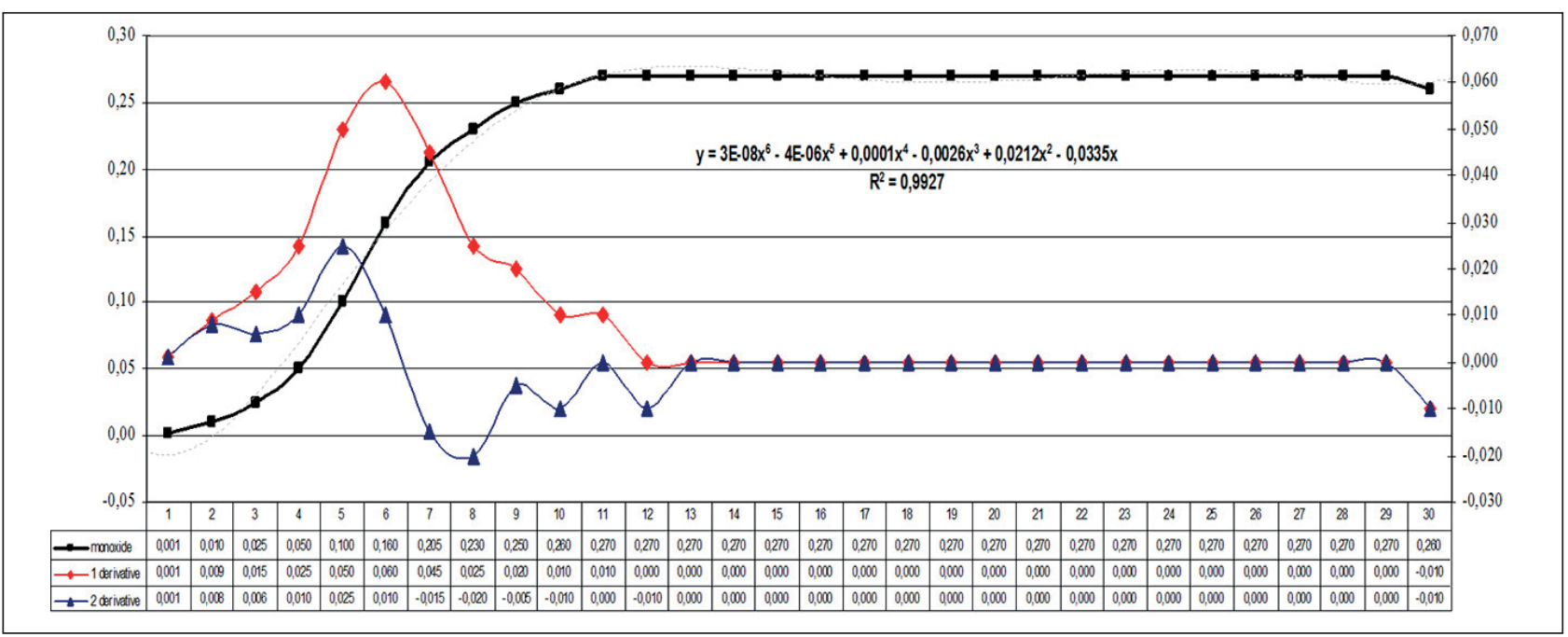

Fig. 4. Graph of dependence of the volumetric average concentration of carbon monoxide

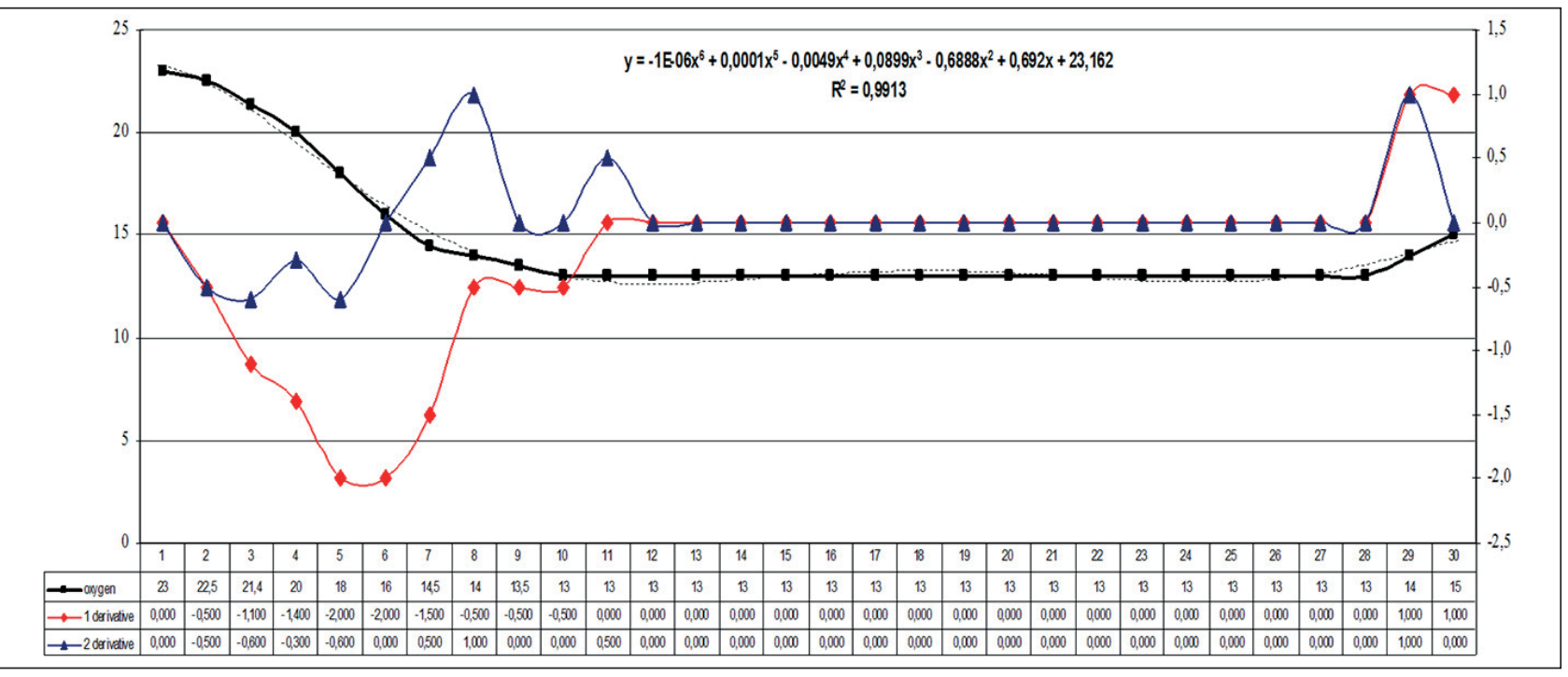

Fig. 5. Graph of the dependence of the average volumetric concentration of oxygen 


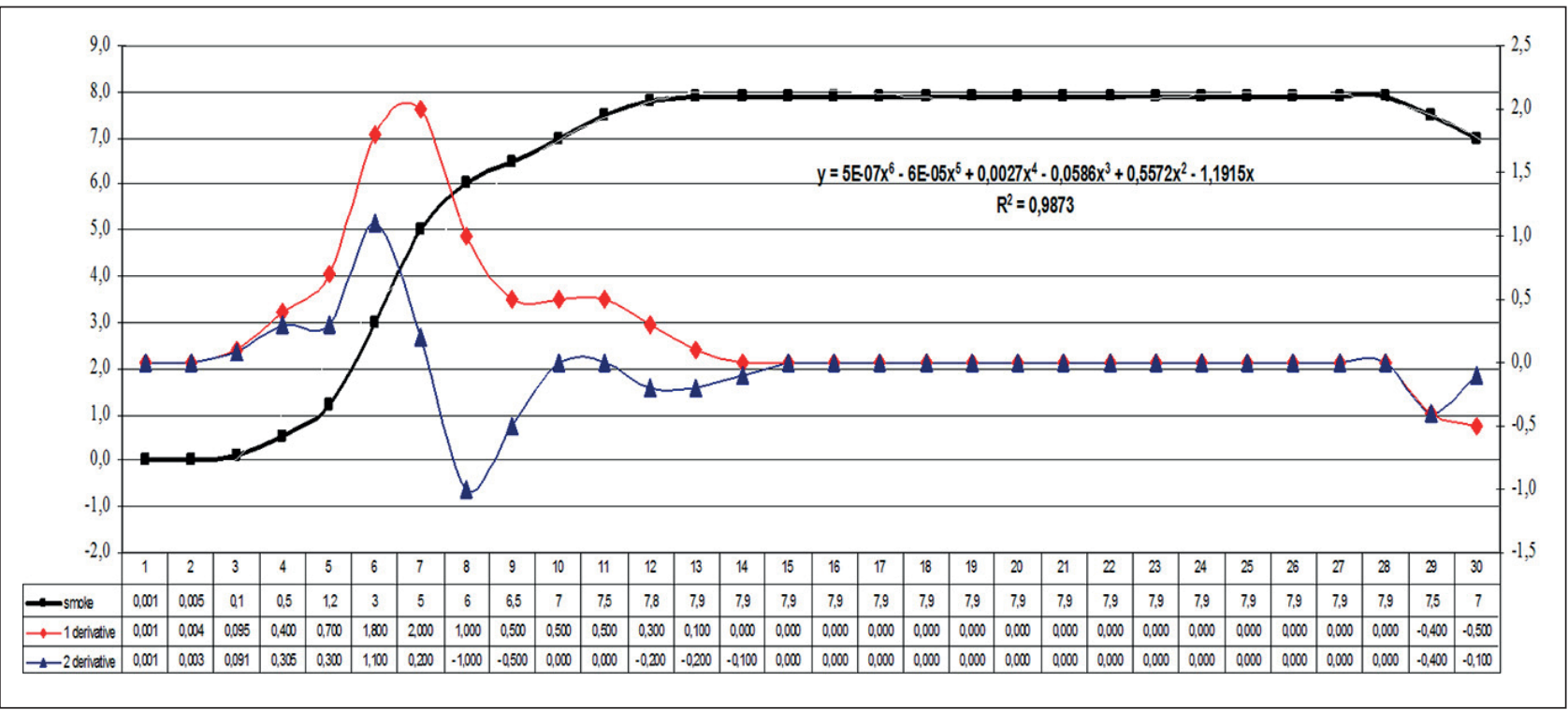

Fig. 6. Graph of dependence of the average volume optical density of smoke

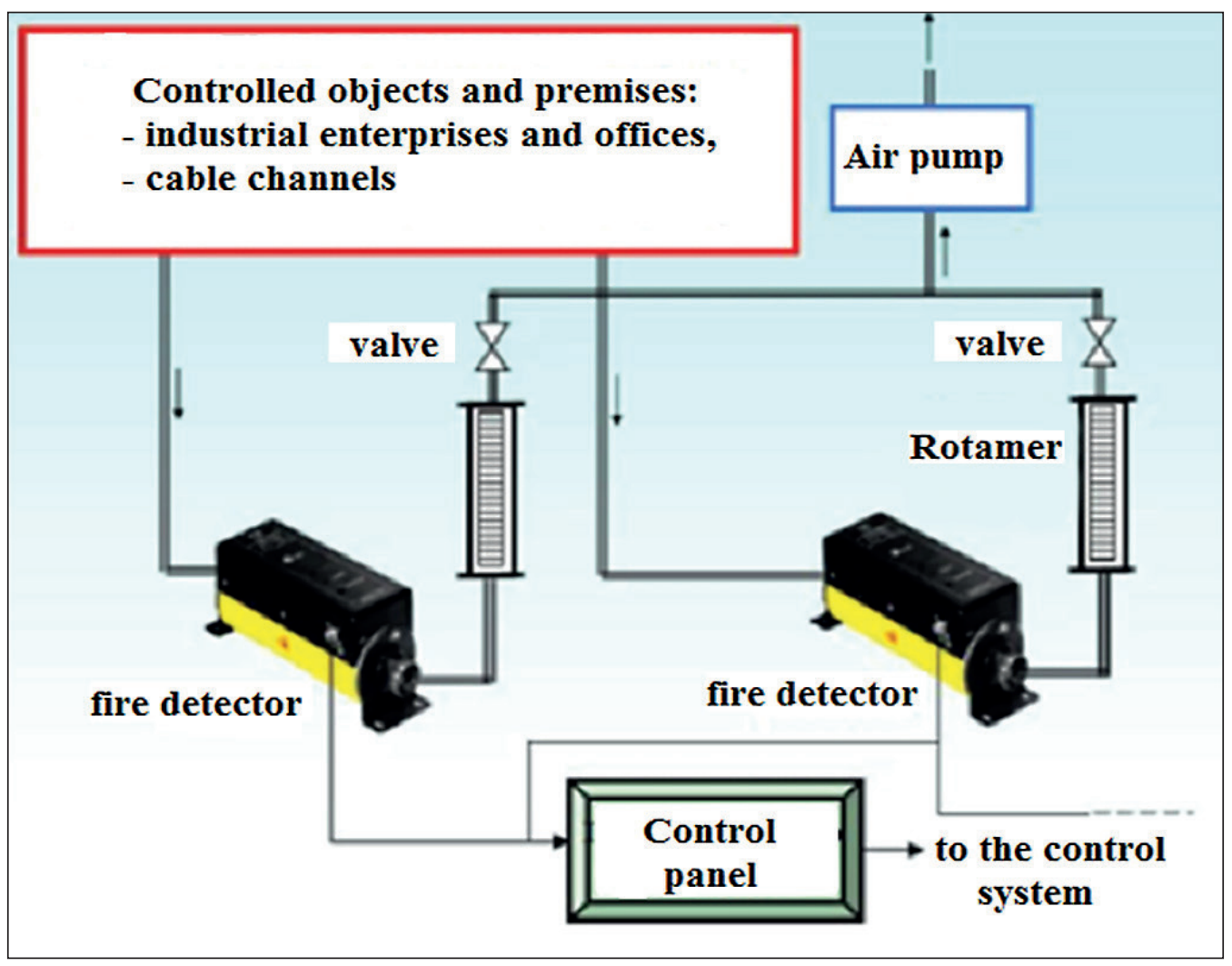

Fig. 7. Aspiration fire alarm system

Currently, a number of devices are being produced that record the quality of the electricity received and used, for example, the domestic LPW-305 device or the stationary analyzer of the amount and quality of electrical energy Circutor CVM series, which provide measurements of standarting of power quality indicators (PQI), necessary for calculating and visualizing the share of high-quality electricity [16,17]:

- the range of voltage change,

- steady-state voltage deviation, 
- flicker dose,

- coefficient of the $\mathrm{n}$-th harmonic component of voltage,

- the distortion factor of the sinusoidality of the voltage curve,

- coefficient of non-symmetry of voltages along the zero sequence,

- coefficient of non-symmetry of voltages in reverse sequence,

- the duration of the voltage dip.

- frequency deviation,

- coefficient of temporary overvoltage,

- impulse voltage.

It would seem that the introduction of "intelligence" into the electricity meter should lead to the fact that consumers will pay only for high-quality electricity, and "smart houses" [18] and the systems automated electricity metering (SAEM) may will become systems of quality and energy saving that protects the population of Russia from "defects in the production and supply" of electricity [19], including a change in the payment tariff and a fine for the supply of "substandard energy-resources" [20]. However, this did not happen, since the basic principle of automation was violated, formulated back in the last century by Academician V.M. Glushkov in the form of "prohibition of automation of the disorder" [21].

Moreover, despite the established (also in the last century) regularities of the occurrence of fires from electrical appliances if violation of the PQI [14], as well as the justification (already in this century) of the dialectical unity of "electrical benefits and of fire-electric harm", neither SAEM, nor "smart house" do not solve the problems of fire safety of objects and their consumers, because the "poor quality" of electricity is not recorded, as and the change for this reason of probability of fire from electrical devices, i. e. of the fire-electric harm (FEH) determining by the formula [22]:

$$
\mathrm{FEH}=\mathrm{Re} \cdot \mathrm{W}=\mathrm{Rpd} \cdot \mathrm{Wpd}+\mathrm{Rud} \cdot \mathrm{Wud},
$$

where $\mathrm{W}$ is the total amount of electricity supplied to the consumer during the time $\mathrm{t}$; Wpd - the amount of consumed electricity with permissible deviations; Wud - the amount of consumed electricity in case of unacceptable deviations; $\mathrm{Re}-$ the average probability of a fire from electrical devices; Ppd - the probability of an electrical devices fire with permissible deviations; Rud - the probability of a fire in an electrical devices with unacceptable deviations.

A system analysis of this approach showed that the probabilities indicated in formula (4) should be updated by energy supervision annually, using the data of the Ministry of Emergency Situations of Russia on the statistics of fires at facilities for electrical reasons. This interaction is due, firstly, by the fact that the probabilities of failures of electrical appliances are of a nonlinear nature, depending on the operating conditions of electrical radioelements (ERE) in them, the failure rates of which are described by equation of the Arrhenius-Eyring [23]:

$$
\lambda=A(P, V, N, F) \frac{\mathrm{k} T}{h} \cdot \exp \cdot\left(-\frac{E_{a}}{\mathrm{k} T}\right) \cdot \exp \cdot[f(H)],
$$

where $\lambda$ - is the current failure rate of the element, $1 /$ hour; $\mathrm{A}=\mathrm{ki} \cdot \lambda_{\mathrm{o}}-$ product of dimensionless coefficients depending on pressure, humidity, vibrations, etc.) by the failure rate during storage $(\lambda \mathrm{o}), 1$ /hour; $\mathrm{k}$ - Boltzmann's constant, $1,38 \cdot 10^{-23} \mathrm{~J} / \mathrm{K} ; \mathrm{T}-$ element temperature, ${ }^{\circ} \mathrm{K} ; \mathrm{h}-$ is Planck's constant, $6,626 \cdot 10^{-34}$ $\mathrm{J} \cdot \mathrm{s} ; \mathrm{E}_{\mathrm{a}}$ - effective activation energy of failure, $\mathrm{J} ; \mathrm{f}(\mathrm{H})-$ function of non-thermal (energy) load.

secondly, by the fact that fire hazardous failures (short circuit, open circuit, electrical breakdown) are hidden, at least an order of magnitude "deeper" than parametric failures described by equation (5), which requires special methods for their determination [23, 24],

thirdly, and this is the main thing, the ignition of ERE and the spread of fire in an electrical devices in the event of a fire hazardous failure is described by a system of nonlinear equations (6) of Semenov, Zeldovich and FrankKamenetsky, which include non-latent indicators of the fire hazard of substances and materials (flammability groups, degree fire resistance, etc.), from which the ERE are made, and their physicochemical characteristics [25], including protective coatings [26], which can be determined with a BETA-analyzer [22, 27, 28].

$$
\left\{\begin{array}{l}
\mathrm{Ze}=\sqrt{2 \lambda_{\mathrm{B}} \frac{\mathrm{RT}_{\Pi}^{2}}{\mathrm{E}_{\mathrm{a}}} \cdot \mathrm{H} \cdot \mathrm{K} \cdot \exp \left(-\frac{\mathrm{E}_{\mathrm{a}}}{\mathrm{RT}_{\Pi}}\right) ;} \\
\mathrm{Se}=\frac{\mathrm{Q} \cdot \mathrm{V}}{\mathrm{S} \cdot \alpha} \cdot \frac{\mathrm{E}_{\mathrm{a}}}{\mathrm{RT}_{\Pi \mathrm{O}}^{2}} \cdot \mathrm{K} \cdot \exp \left(-\frac{\mathrm{E}_{\mathrm{a}}}{\mathrm{RT}_{\Pi \mathrm{O}}}\right) ; \\
\mathrm{F}_{\mathrm{K}}=\frac{\mathrm{Q} \cdot \mathrm{r}^{2}}{\lambda_{\mathrm{O}}} \cdot \frac{\mathrm{E}_{\mathrm{a}}}{\mathrm{RT}_{\mathrm{O}}^{2}} \cdot \mathrm{K} \cdot \exp \left(-\frac{\mathrm{E}_{\mathrm{a}}}{\mathrm{RT}_{\mathrm{O}}}\right) ;
\end{array}\right.
$$

where $\mathrm{Ze}$ - is the Zeldovich criterion (critical heat flux density); $\lambda \mathrm{gf}$ - coefficient of thermal conductivity of the gas phase; $\mathrm{R}-$ is the gas constant; $\mathrm{Tf}-$ is the furnace temperature; $\mathrm{E}_{\mathrm{a}}$ - is the activation energy for pyrolysis of the sample; $\mathrm{H}$ - is the thermal effect of the reaction in the gas phase; $\mathrm{K}$ - pre-exponent; $\mathrm{Se}$ - Semenov's criterion $(\mathrm{Se}=0.368) ; \mathrm{Q}-$ is the heat supplied to the sample; $\mathrm{V}$ - is the current sample volume; $\mathrm{S}$ - is the current surface area of the sample; $\alpha$ - is the current heat transfer coefficient of the sample; Tss - is the temperature of the sample surface; Fk - criterion of Frank-Kamenetsky 
$(\mathrm{Fk}=2.00) ; \mathrm{r}-$ is the linear size of the sample; $\lambda_{\mathrm{o}-}$ coefficient of thermal conductivity of the sample; Ts - is the temperature of the sample.

Therefore, the determination of the probabilities indicated in formula (5) is possible only when using the fire statistics databases of the Ministry of Emergency Situations of Russia in each specific region, as well as their processing by the method of time series analysis [29], and this approach can be implemented in the residential sector only with the help of "intellectualization" electric meters [30], with the interaction of energy supervision and state supervision [31].

\section{METHODS, MODELS AND MEANS OF DETECTING AND SUPPRESSION ELECTRIC FIRE HAZARD}

Considering the above, the obvious solution, i.e. "elimination of disorder in the power supply" was the development of a method for determining fire and electrical harm and hazardous fire factors using an electric meter-detector protected by RF patents $[22,30]$, by integrating the above sensors (heat, smoke, oxygen and carbon monoxide) into an electric meter and their docking with an aspiration system, which made it possible to ensure early detection of a fire in an apartment or an individual residential building where such an electric meter-detector (EMD) is installed (Fig. 8), as well as to turn on the sound notification of a fire and send a call to the nearest fire department by radio channel or by means of cellular communication [31].

However, for the normal functioning of electrical appliances in the residential sector and ensuring their fire safety, especially in rural areas, where PQIs are constantly violated [31, 32], control over the quality of consumed electricity is not enough - it is advisable to "smooth out the quality of delivery" of electricity to the consumer, i.e. to improve the PQI at the place of electricity consumption, which is successfully performed by reactive power regulators [33, 34].

Contactor capacitor units are most widely used due to their facilitated implementation and low cost compared to thyristor capacitor units. However, if the load has a sharply variable character, then thyristor capacitor units are used to compensate for reactive power, because they, firstly, have the highest speed, and secondly, the switching of capacitors in them occurs at zero current, which significantly increases the service life of both capacitor banks and the entire installation as a whole. In this case, the following reactive power compensation schemes are distinguished at the connection point $[33,34]$ :

- general - at the input of the object (enterprise, micro district, etc.);

- group - on the power supply line of a group of consumers of the same type (a group of residential buildings, etc.);

- individual - a capacitor unit is installed in close proximity to the consumer for control cosine phi.

In the residential sector, especially in rural areas, an individual compensation scheme is more preferable because allows you to compensate for reactive power directly at the place of its origin and consumption of electricity, without causing an overflow of reactive energy in power lines, and in the case of a constant power factor of the consumer, fully compensate for reactive power using a capacitor bank (Fig. 9). In this case, it is possible to implement both lateral and longitudinal compensation $[35,36]$.

Considering that recently, electrical household appliances with electric motors (refrigerators, washing machines, split systems, vacuum cleaners, electric meat grinders, etc.) have begun to dominate in the structure of household appliances, i.e. the nature of the load in

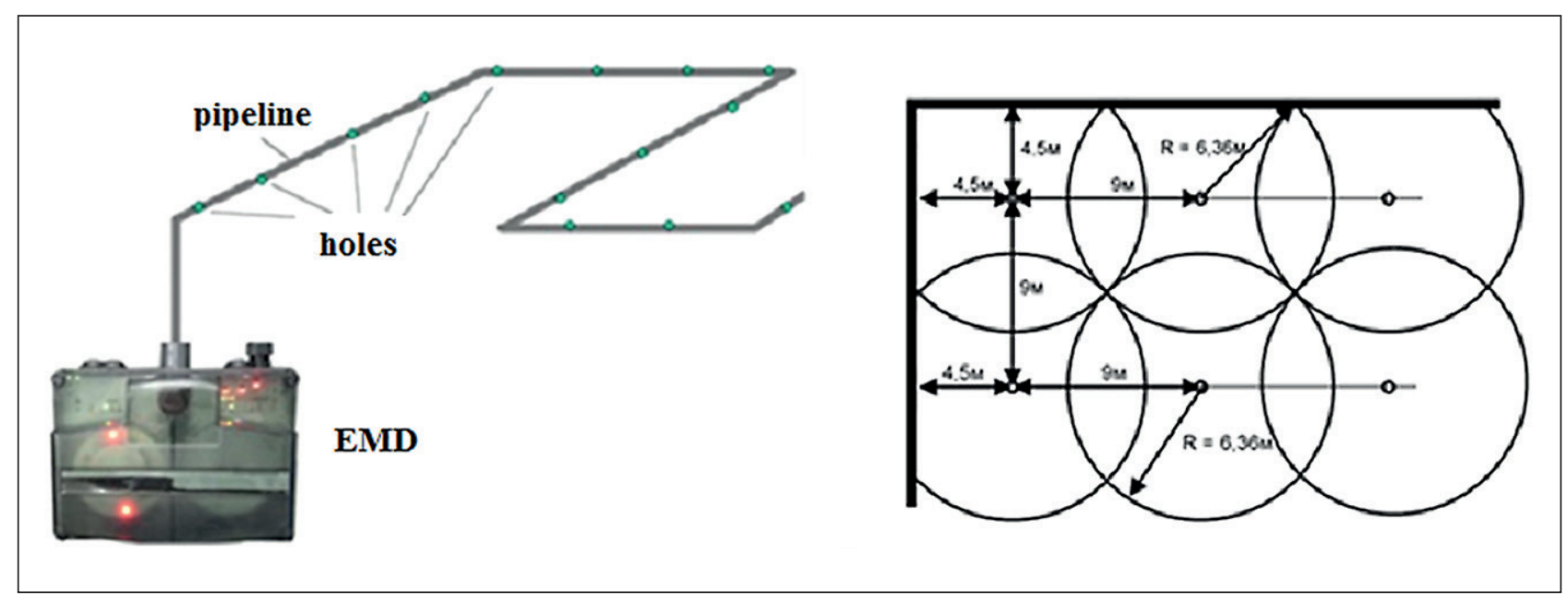

Fig. 8. Scheme of aspiration with electric meter-detector (EMD) 


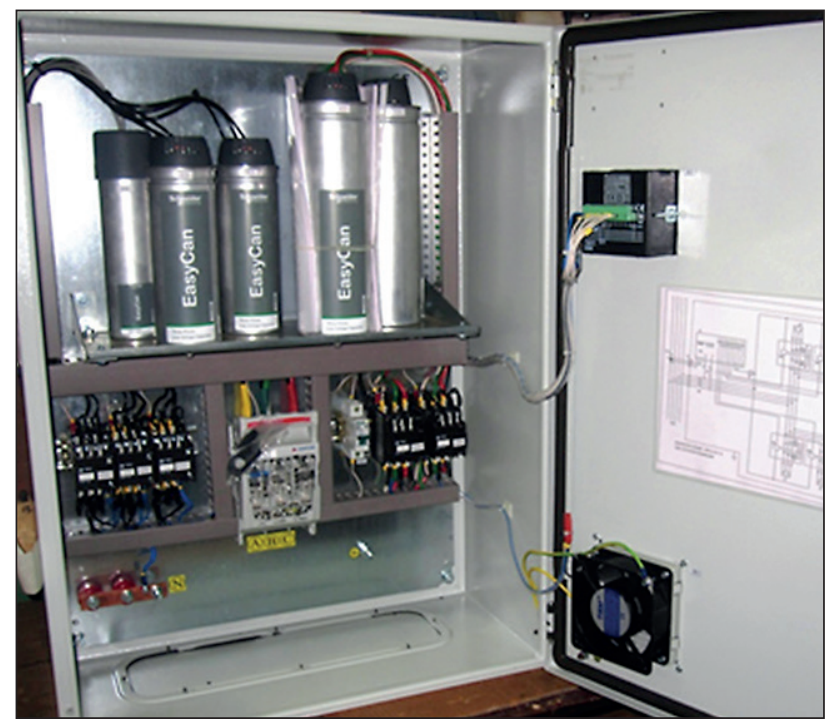

Fig. 9. Capacitor reactive power compensator (CRPC)

the residential sector has become predominantly by active-inductive, it is advisable to use capacitor reactive power compensators (CRPC), the main advantages of which are [33, 34]:

- small losses of active energy (within $0.3-0.45 \mathrm{~kW} / 100$ kvar);

- low weight (does not require a foundation);

- simple and inexpensive operationservis;
- an increase or decrease in the number of connected capacitors depending on the change in the cosine of the voltage and current shift angle;

- compactness, which makes it possible to install the unit in any place (next to electrical equipment, electricity meter, etc.).

In addition to maintaining the set power factor, and "smoothing" fluctuations in phase voltage, current and generation of reactive energy during the hours of minimum and maximum loads (Fig. 10), reactive power compensator [33, 34]:

- constantly monitors the change in the amount of reactive power in the compensated circuit;

- excludes overcompensation and its consequence overvoltage in the network;

- monitors the main indicators of the compensated network;

- checks the operation of all elements of the CRPC and the mode of its operation.

Many authors believe that the use of CRPC in single-phase household networks is not effective because individual "single-phase consumers" pay only for active power, and reactive power compensation reduces the total consumption by a few percent [36]. At the same time, regulatory documents also do not require that reactive load compensation be provided for in residential and public buildings [37].

However, from the point of view of the occurrence of the FEH, the "smoothing" of voltage and current

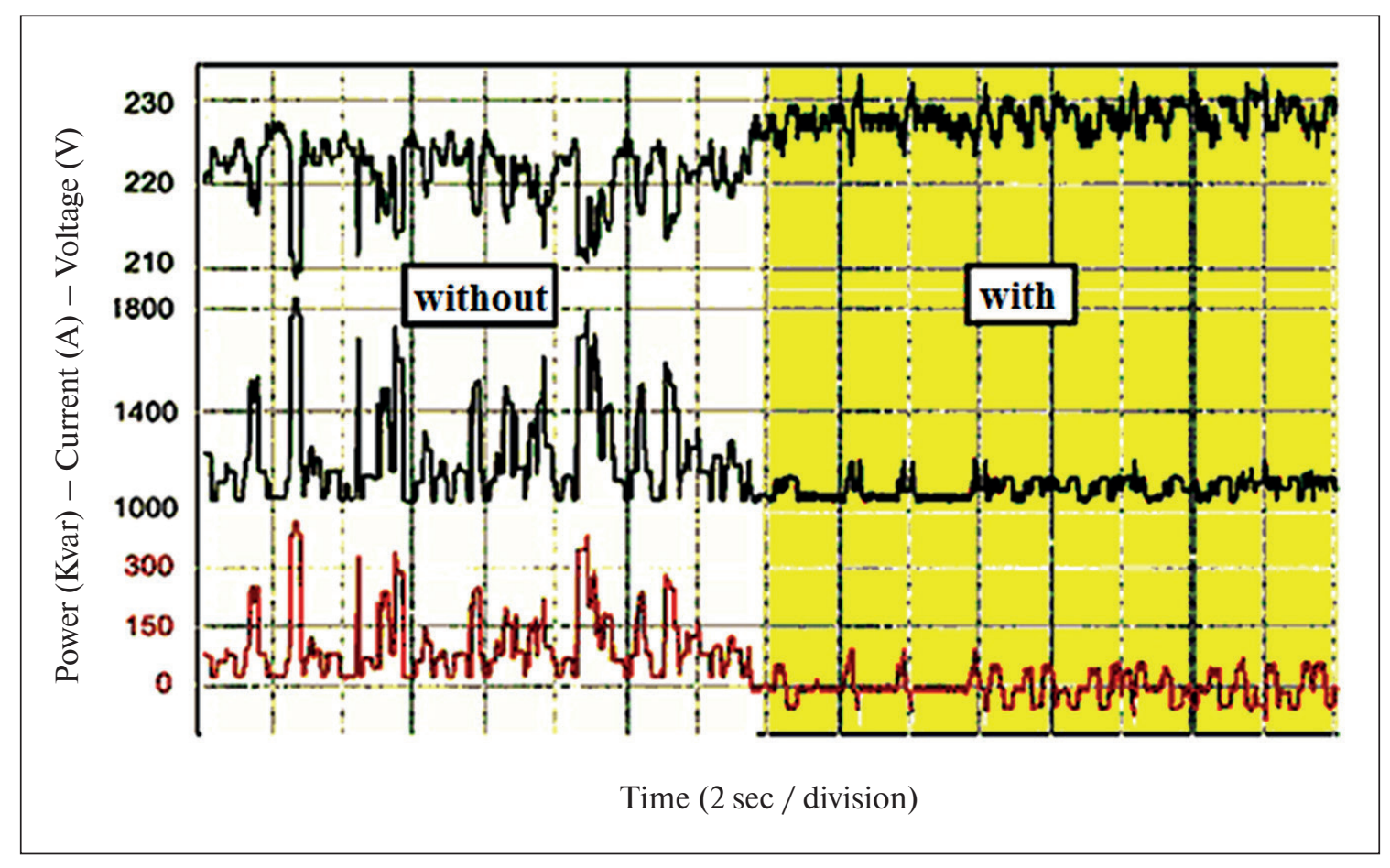

Fig. 10. Graphs of voltage, current and power consumption with and without CRPC 
achieved in this case, allows more than an order of magnitude to reduce the probability of fire-hazardous failures in household electrical appliances, and, consequently, to reduce the number of fires and socio-economic losses from them [2, 14, 31, 38].

For automatic control of reactive power compensation, i.e. connecting / disconnecting capacitors in the battery (Fig. 11), the following method was used to determine the current cosine "phi", protected by the copyright certificate [39]:

$$
\begin{aligned}
& \cos \varphi=\frac{2 U_{2}^{2}-U_{3} U_{1}-U_{1}^{2}}{2 U_{2} \sqrt{U_{2}^{2}-U_{3} U_{1}}} \cdot \frac{2 I_{2}^{2}-I_{3} I_{1}-I_{1}^{2}}{2 I_{2} \sqrt{I_{2}^{2}-I_{3} I_{1}}}+
\end{aligned}
$$

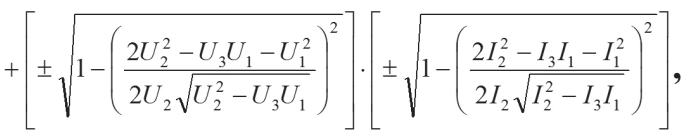

where U1, U2 U3 - instantaneous values voltage of the phase of the consumed electricity at equidistant intervals during a half-period; I1, I2, I3 - instantaneous values current of phase of the consumed electricity at equidistant intervals during a half-period.

Each KPS-0.55-0.41-2UZ capacitor with a capacity of 10 microfarads is connected by MOS3041 optosimistors, and the MOS3041 optosimistors are controlled by supplying a certain voltage level $(0.4 \mathrm{~V}, 0.8 \mathrm{~V}, 1.2 \mathrm{~V}$...4 V) from a digital-to-analog of converter (DAC) of the controller to the gates of all field-effect transistors 2P304A. The 2P304A modes are selected so that at a level of $0.4 \mathrm{~V}$, the $1^{\text {st }}$ transistor opens, which leads to the "ignition" of the LED of the 1st triac and the connection of one $10 \mu \mathrm{F}$ capacitor, at a level of $0.8 \mathrm{~V}-$ the $1^{\text {st }}$ and $2^{\text {nd }}$ and etc., up to $4 \mathrm{~V}$, which connect the entire $90 \mathrm{uF}$ battery. To provide such a "step control", we calculated the dividers from the resistances, which set the necessary operating modes of field-effect transistors for a singlephase network, taking into account the limitation for the digital-to-analog converter (DAC) of the load value, including the last stage (Fig. 11), which is controlled by a separate channel DAC, and also serves to turn off the power supply of an apartment/individual house in a fire-hazard mode of electricity consumption and when ignition [2, 35, 38].

For a 3-phase network, which is used in residential high-rise buildings, it is enough to install 3 capacitor banks of 7 same capacitors in each, with the same control of each separately, which will require sixe DAC channels $[2,38]$.

Thus, supplementing the EMD with an oxygen sensor and a reactive power compensation unit (RPCU), as well as a more powerful controller with multichannel ADC and DAC, we obtain (Fig. 12) an electric meter-detector-suppressor (EMDS) FEN, i.e. a decrease in the second term in formula (4) and, thereby, due to low-quality electricity, of the probability, of fire from all electrical appliances in the residential sector $[2,14,24]$.

\section{RESULTS AND DISCUSSION}

The developed electric meter-detector-suppressor (Fig. 12) contains in its housing:

- a chamber with a suction fan (1) and sensors in it (heat, smoke, oxygen and carbon monoxide), connected to the pipeline of the aspiration system,

- controller (2) with multichannel analog-to-digital converter (ADC) and digital-to-analog converter (DAC), with LCIP visualization module (3) and GSM radio modem (4),

- reactive power compensation unit (RPCU) with power supply and battery.

Unlike the patented EMD solutions [22,30], the units for measuring the consumed electricity and its quality, calculating of fire-electric harm and identifying hazardous fire factors are implemented on the controller (2), as software modules, performing the following functions $[2,35,38,40]$ :
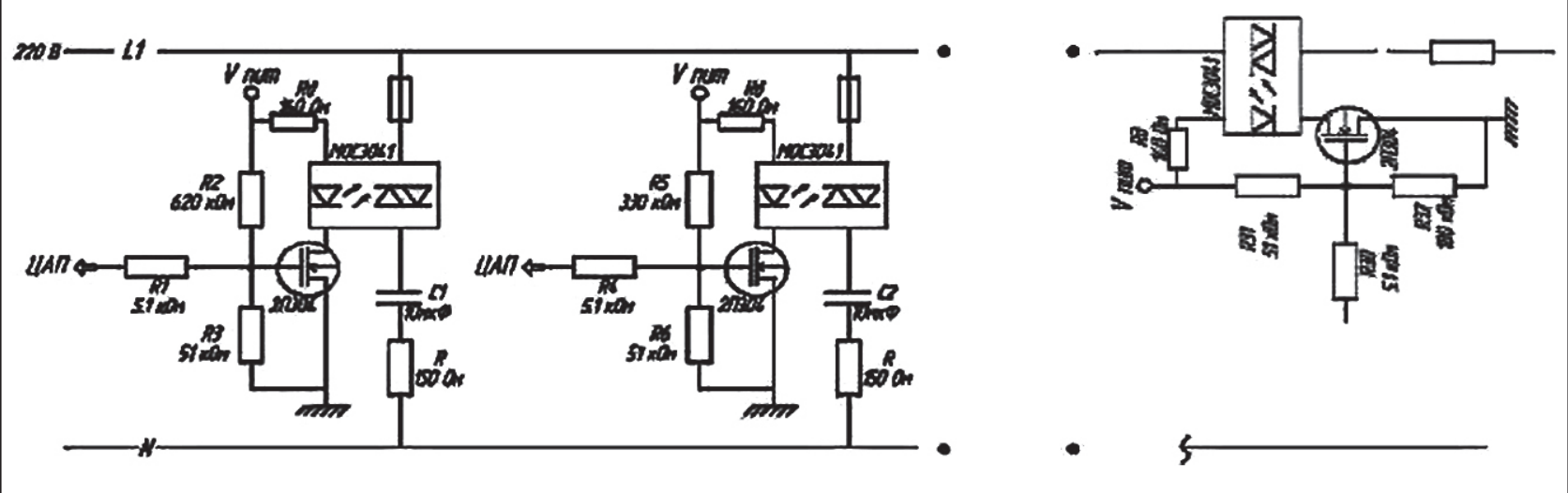

Fig. 11. Schematic diagram of the capacitor control unit for one phase 


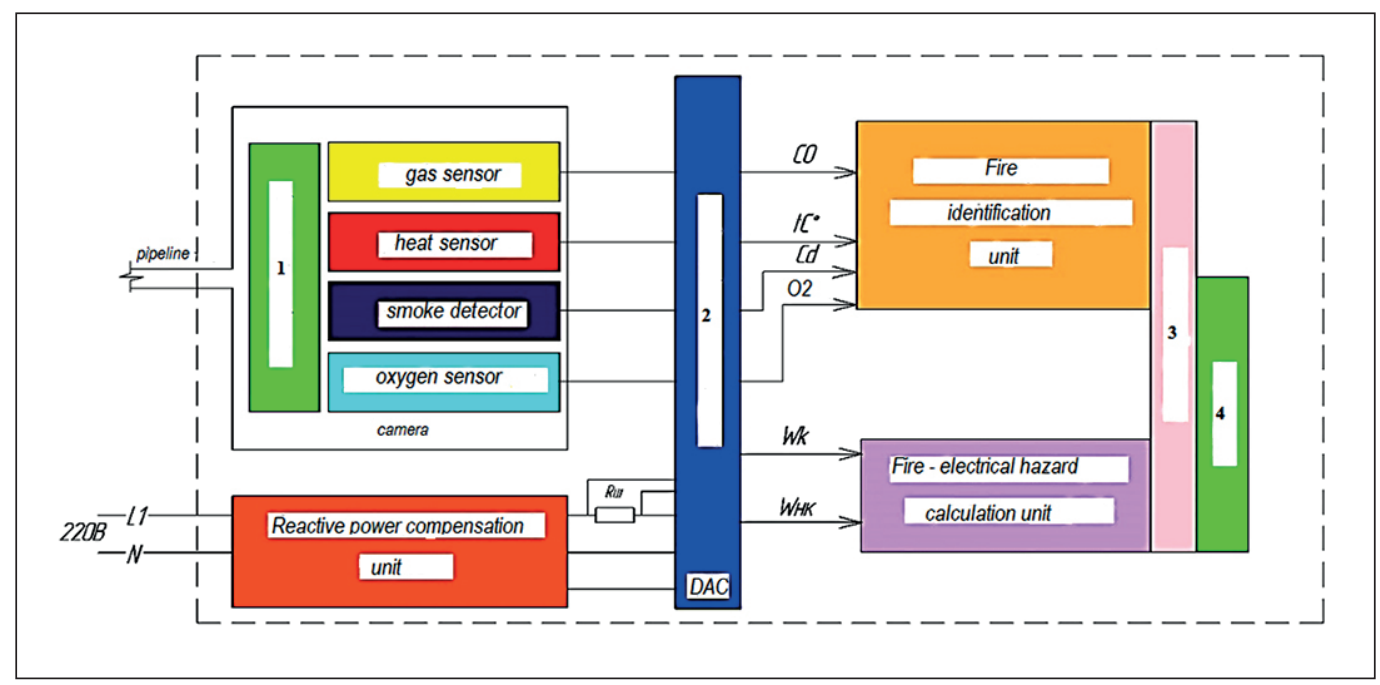

Fig. 12 Block diagram of an electric meter-detector-suppressor (EMDS):

1 - electric fan; 2 - controller with multichannel ADC and DAC; 3 - liquid crystal indicator with piezo-module of audio-video information (LCIP-module); 4 - GSM radio modem

- process the data of the ADC channels to which the specified sensors are connected, calculating and recording in real time (in the flash memory and/or on the flash card) the temperature and concentration of the FEH and oxygen [9-12] in the protected rooms (in the air, pumped through the chamber),

- process the data of the ADC channels, which are connected to the current shunt (Fig. 12) of the shutdown stage (Fig. 11), calculating and recording in real time (in the flash memory and / or on the flash card) PQI [16] and coefficients power [39], summarizing and visualizing on the LCDP-module the consumed electricity (high-quality and low-quality) and the averaged current cosine "phi",

- calculate the fire-electrical harm (FEH) according to the formula (4), visualizing its averaged value on the LCIP-module (3), and control the operation of the RPCU, according to the power factor calculated according to the formula (5),

- form and transmit using a GSM radio modem (4) to the power organization and / or management company data blocks on the consumed electricity, in accordance with the established time periods and at their request, as well as to the supervisory authorities (fire, electric), in fire-threatening cases, with unacceptable quality and power outages,

- identify the HFF by the synchronous growth of the function (2) of temperature (Fig. 1), the function of the average volumetric concentration of carbon monoxide (Fig. 4) and the average volumetric optical density (smoke) of the air (Fig. 6), with synchronous with a decrease in the oxygen concentration (Fig. 5) in the protected premises, after that turn on light and sound alarms, generating and transmitting a message about the fire to the fire brigade using a GSM radio modem (4), as well as to the owner of the property and to the management company,

- the power supply of the protected premises is turned off with the help of a triac (Fig. 11) in the RPCU, in case of a fire-threatening mode of electricity consumption and / or in case of its unacceptable quality, as well as in case of detection of a HFF in the protected premises.

At the same time, calculating the FEH according to formula (4), the software module calculates the changes in the probabilities ( $\mathrm{Pd}$ and $\mathrm{Pnd}$ ) and their deviations $(\Delta \mathrm{Pe}, \Delta \mathrm{Pd}$ and $\Delta \mathrm{Pnd}$ ), from the average statistical data that must be updated by the energy supervision according to the data of fire supervision, during an annual check EMDS.

\section{CONCLUSION}

As a result of a system analysis of the problems of safe life in the residential sector (in apartments in residential buildings and in individual residential houses) of cities and towns of the Russian regions, fundamental shortcomings in the organization and automation of metering of consumed electricity in the residential sector were revealed.

On the basis of the developed probabilistic-physical approach to the occurrence of fire-electrical harm (FEH) in the residential sector when electricity is consumed, a sequential systemic synthesis of the method and means of diagnostics of HFF with nanotechnologies for its suppression was carried, with using of electric meter-de- 
tector-suppressor (compensation unit reactive power), which, together with the aspiration method for detecting the HFF, prevents the occurrence of a fire for electrical reasons, by timely disconnecting the power supply to the protected premises, and also provide early detection of ignition in them due to other reasons (careless handling of fire, etc.) ).

The proposed approach, according to the authors, is designed to "eliminate clutter" in the supply and metering of electricity to the residential sector, as well as to optimally automate the power supply and fire alarm in the residential sector, regardless of the structures of energy supply/management companies and of territorial emergency and supervisory services.

The proposed method and EMDS enable to implement it using the reinvestment model of the system of adaptive fire-electric taxation of individuals in the residential sector in the shortest possible time [20, $31,32,38]$.

The studies have shown that the proposed approach can be implemented at the objects of trade, health care, education, science and culture [3, 12, 20-25].

\section{REFERENCES}

1. Meshalkin E.A. Fire safety of residential buildings. Security systems. 2013; 1: 106-109.

2. Perikov A.V. System analysis and nanotechnology of safety in engineering systems of residential high-rise buildings. Nanotechnologies in Construction. 2018; 10(2): 114-130. Available from: doi: 10.15828/2075-8545-2018-10-2-114-130.

3. Boguslavsky E.I., Belozerov V.V., Boguslavsky N.E. Forecasting, analysis and assessment of fire safety. Rostovon-Don: RSSU; 2004.

4. Chlenov A.N., Fomin V.I., Butsynskaya T.A., Demekhin F.V. New methods and technical means of fire detection . Moscow: Academy of State Fire Service of the Ministry of Emergency Situations of Russia; 2007.

5. Yu-Chun Wen, Fa-Xin Yu, Xiao-Lin Zhou, Zhe-Ming Lu. A vector quantization based automatic fire detection system. Information Technology Journal. 2010; 9(4): 758-765. Available from: doi: 10.3923/itj.2010.758.765.

6. Turgay Çelik, Hasan Demirel. Fire detection in video sequences using a generic color model. Fire Safety Journal. 2009; 44(2): 147-158. Available from: doi: 10.1016//j.firesaf.2008.05.005.

7. Chlenov A.N., Butsynskaya T.A., Zhuravlev S.Yu., Nikolaev V.A. On the effectiveness of the functioning of a multicriteria fire detector. Fire and Explosion Safety. 2016; 25(12): 55-60. Available from: doi: 10.18322/PVB.2016.25.12.55-60.

8. Belozerov V.V., Oleinikov S.N. Radio detectors of technosphere danger and its navigation with an Internet system of their functioning. Fundamental research. 2013; 10: 2843-2853.

9. Mozgovoy N.V., Zaitsev A.M. Analysis of functional dependences of the temperature curve of a standard fire. Scientific Bulletin of VGASU. 2008; 3: 196-199.

10. Koshmarov Yu. Prediction of hazardous factors of fire in the room. Moscow: AGPS Ministry of Internal Affairs of the Russian Federation; 2000.

11. GOST 12.1.004. Fire safety. General requirements. Moscow: Ed. standards; 1992.

12. GOST R 12.3.047-2012. Fire safety of technological processes. General requirements. Control methods. Moscow: Standartinform; 2014.

13. Recommendations for the use of VESDA aspirating smoke detectors. Parts 1, 2 and 3. Moscow: VNIIPO EMERCOM of Russia; 2003.

14. Belozerov V.V., Topolsky N.G., Smelkov G.I. Probabilistic-physical method for determining the fire hazard of radio-electronic equipment. In: Scientific and technical support for fire-prevention and rescue operations: Materials of the XII All-Russian Scientific and Practical Conference. Moscow: VNIIPO; 1993. p. 23-27.

15. Kushnarev F.A., Reshetnikov Yu.M., Nikiforova V.N., Ermakov V.F. Statistical analyzer of quality and metering of electricity consumption. Russian Federation Patent 2260842. 2008-07-15.

16. GOST 13109-97. The quality of the electrical network. General requirements. Moscow: Ed. standards; 1997.

17. Telemetric meter of electrical parameters of quality, power and amount of electrical energy LPW-305. Operation manual: DLIZH.411722.0001 OM. Moscow: LLC "L Card”; 2011.

18. Avdeev A.S., A.I. Gerasimova The main problems of programming systems "Smart House". Prospects for Science. 2014; 10: 62-65.

19. Loskutov A.B., Gardin A.I., Loskutov A.A. Automated system for monitoring and metering of electricity. Nizhny Novgorod: NGSTU; 2018. 
20. Belozerov V.V., Oleinikov S.N. On the issue of an adaptive fire and energy tax in ensuring fire safety. In: Improvement of the theory and methodology of finance and taxation: Materials of International Scientific and Practical Conference. Volga Research Center. Yoshkar-Ola: Colloquium; 2012. p. 106-111.

21. Encyclopedia of Cybernetics. Ed. acad. Glushkov V.M. Vol. 1. Kiev: Academy of Sciences of the Ukrainian SSR (Chief editor USE); 1974.

22. Belozerov V.V., Oleinikov S.N. Method for determining fire and electrical harm and hazardous factors of fire using an electric meter-detector. Russian Federation Patent 2622558. 2012-09-07.

23. Belozerov V.V. Experimental methods for assessing the quality, reliability and safety of electrical appliances. Technologies of technosphere safety. 2009; 5. Available from: http://agps-2006.narod.ru/ttb/2009-5/09-05-09.ttb.pdf [Accessed $10^{\text {th }}$ April 2021].

24. Belozerov V.V., Lyubavsky A.Yu., Oleinikov S.N. Models for diagnostics of reliability and safety of SVT and ACS of technosphere objects. Moscow: Publishing House of the Academy of Natural Sciences; 2015. 130 p.

25. Belozerov V.V. On the expediency of revising the main fire standards. In: Proceedings of Annual International Scientific and Technical Conference "Security Systems-2014". Moscow: AGPS EMERCOM of Russia; 2014. p. 274-282.

26. Belozerov V.V., Golubov A.I., Kalchenko I.E., Nguyen T.A., Topolsky N.G. Nanotechnology for testing and diagnostics of materials, structures and elements of engineering systems of buildings with fire retardant coatings. Part 1. Nanotechnologies in Construction. 2020; 12(3): 174-184. Available from: doi: 10.15828/2075-8545-2020-12-3-174-184.

27. Builo S.I., Belozerov V.V., PrusYu.V. Combined thermogravimetric and acoustic emission diagnostics of the stages of thermal destruction of substances and materials. Defektoskopiya. 2008; 44(3): 71-74. Available from: doi: 10.1134/S1061830908030078.

28. Belozerov VV, Belozerov Vl. V. Baro-electro-thermo-acoustic method of analysis of substances and materials and BETA-analyzer, which implements it. In: Fundamental foundations of physics, chemistry and dynamics of scienceintensive technological systems for forming and assembling products: Proceedings of the Scientific Symposium of Mechanical Engineers. Rostov-on-Don: DSTU; 2019. p. 298-306.

29. Belozerov V.V., Oleinikov S.N. On spatio-temporal statistical analysis of fires. Modern problems of science and education. 2013; 4: 58.

30. Oleinikov S.N. Electricity meter - fire and electrical hazard detector. Russian Federation Patent 2013117242. 2013-16-04.

31. Belozerov V.V., Dolakov T.B., Oleinikov S.N., Perikov A.V. Synergetics of life safety in the residential sector. Moscow: Publishing house of the Academy of Natural Sciences, 2017. Available from: doi: 10.17513/np.283.

32. Belozerov V.V., Dolakov T. B. Synergetics of automation of protection of the residential sector in rural areas. In: Innovations and engineering in the formation of investment attractiveness of the region: Proceedings of the II Open International Scientific and Practical Forum. Rostov-on-Don: DSTU, SFedU; 2017. p. 362-371.

33. Bely V.V. Electromagnetic compatibility of elements of power supply systems containing reactive power compensation devices. Bulletin of the Altai State Agrarian University. 2009; 6(56); 62-65.

34. Condensing unit for reactive power compensation - KRM 0.4. Moscow: LLC AllianceEnergoService; 2014.

35. Belozerov V.V., Dolakov T.B., Belozerov Vl.V. On safety and prospects of electrical heating in individual residential buildings. Modern science-intensive technologies. 2017; 11: 7-13.

36. Shishkin S.A. Compensation of reactive power and electricity losses in rural distribution networks $6(10) / 0.4 \mathrm{kV}$. Mechanization and electrification of agriculture. 2003; 10: 21-23.

37. Ministry of Fuel and Energy of the Russian Federation. RD 34.20.185-94. Instructions for the design of urban electrical networks. Moscow; 1995.

38. Perikov A.V. Model of an automated microsystem for suppressing fire-electric harm. International student scientific bulletin. 2018; 3-3. Available from: http://www.eduherald.ru/ru/article/view?id=18323 (Accessed ${ }^{\text {rd }}$ April 2021).

39. Melent'ev V.S., Baskakov V.S., Shutov V.S. Method for determining the power factor. Inventor's Certificate (USSR) No. 1679401 A1, G 01 R21 / 00. 1989-07-18.

40. Belozerov V.V., Denisov A.N., Dolakov T.B., Voroshilov I.V., Nikulin M.A., Oleinikov S.N., Belozerov V.V. Method for early and authenticity detection of hazardous factors of fire, with of suppression of fire-energy harm in residential premises. Application for invention RU 2021122049 of 2021-04-27. 


\section{INFORMATION ABOUT THE AUTHORS}

Valery V. Belozerov, Doct.(Eng.), Associate Professor, Professor of the Department of Automated Control Systems, Don State Technical University, Rostov-on-Don, Russia, ORCID: http://orcid.org/0000-0001-6999-7804, e-mail: safeting@mail.ru

Vladimir V. Belozerov, Cand.Sci.(Eng.), Associate Professor, Department of Automated Control Systems, Don State Technical University, Rostov-on-Don, Russia, ORCID: http://orcid.org/0000-0003-4758-1036, e-mail: isagraf@mail.ru

Timur B. Dolakov, Applicant, Department of Automated Systems and Information Technologies, Academy of the State Fire Service of the EMERCOM of Russia, Moscow, Russia, ORCID: http://orcid.org/0000-0001-7143-5608, e-mail: dolakov23@gmail.com

Mikhail A. Nikulin, Senior Lecturer, Department of Technosphere Safety, State Agrarian University of the Northern Trans-Urals, Tyumen, Russia, ORCID ID: https://orcid.org/0000-0002-7756-3456, e-mail: pojar_2003@mail.ru

Sergey N. Oleinkov, Cand.Sci.(Eng.), Deputy Head of the Faculty of Training Scientific and Pedagogical Personnel, Academy of the State Fire Service of the EMERCOM of Russia, Moscow, Russia, ORCID: https://orcid.org/0000-0002-8316-075X, e-mail: osn-fire@bk.ru

\section{Authors declare the absence of any competing interests.}

Received: 15.03.2021.

Revised: 04.04.2021.

Accepted: 08.04.2021. 